\title{
Sub clinical Vascular Inflammatory Markers, and Carotid Artery Intimal-Media Thickening in Obese Children and Adolescents
}

\author{
Saeed Hammad", Mahmoud El-Gharieb ${ }^{* *}$, Samy Khodeir ${ }^{* * *}$ and \\ Maher Abdel Hafez
}

Department of Pediatrics, Faculty of Medicine, Omer El-Mukhtar University, Lybia $^{*}$, and Departments of Physiology, ${ }^{* *}$ Internal medicine ${ }^{* * *}$ and Pediatrics $^{* * *}$ Faculty of Medicine, Tanta University.

\begin{abstract}
Objectives: Childhood obesity contributes to the development of adult obesity and subsequent atherosclerosis, and cardiovascular disease. Associations between early morphologic and functional vascular changes as Endothelial Dysfunction, and Sub clinical vascular inflammatory soluble markers are in need for intensive assessment especially in obese childhood. The present study aimed to investigate the relationship of morphological vascular status (Carotid Artery intima-media thickness [IMT]) and functional vascular changes as plasma endothelial markers (von Willebrand factor [vWf], soluble intercellular adhesion molecule-1(sICAM-1), soluble vascular cell adhesion molecule-1 (sVCAM-1)), sP-selectin (sE-selectin), and high sensitive C Reactive Protein (hs-CRP) concentrations in obese children, compared with controls. Patients and methods: 35 obese children included 15 males and 20 females, and twenty five healthy lean children of matched age and sex were included in this study as a control. All underwent assessment of morphological vascular status by measuring Carotid Artery intima-media thickness [IMT]) and analysis of plasma endothelial markers ( $v W f$, sICAM-1, sVCAM-1, sP-selectin, hs-CRP concentrations and Eselectin). Results: Our results showed that in comparison with controls, obese children demonstrated significantly increased IMT, We demonstrated that, concentrations of soluble E-selectin, sICAM-1, sVCAM-1, sP-selectin and hs-CRP concentrations were significantly elevated in obese children, whereas $v W f$ showed no significant differences between obese children and controls. Conclusions: The present study documented that subclinical inflammation associated with obesity increase the risk of early atherosclerosis in these children. Sonographic assessment of vascular status and the estimation of soluble endothelial plasma markers, may form a rationale to identify high-risk children susceptible to early atherosclerotic disease and to monitor vascular changes during follow-up studies and therapeutic measures.
\end{abstract}




\section{INTRODUCTION}

The recent epidemic of childhood obesity has become a leading public health problem in Western countries ${ }^{(\mathbf{1})}$ because of the possible later clinical consequences, including cardiovascular disease $\mathrm{e}^{(2)}$ The constellation of cardiovascular risk factors that is frequently associated with obesity in adults has been demonstrated to affect obese children as well. $^{(3)}$ Those children often manifest with left ventricular hypertrophy, type 2 diabetes, hypertension, increased serum concentrations of low-density lipoprotein (LDL) cholesterol and factor VIIIc, and decreased serum concentrations of high-density lipoprotein (HDL) cholesterol $^{(\mathbf{3 , 4})}$. As in adults, the metabolic syndrome ${ }^{(5)}$ and a significant degree of insulin resistance $^{(\mathbf{6})}$ can be observed in obese children. In addition, the risk for developing all of the features of the metabolic syndrome during adult life is four times increased in children who were obese at 7 years ${ }^{(7)}$.

Although the presence of additional risk factors could be relevant in increasing the individual cardiovascular risk profile, recent data suggest that obesity in children per se could worsen cardiovascular prognosis later in life..$^{(\mathbf{8 , 9 , 1 0})}$ Thus, obesity per se has the potential to promote atherosclerotic plaque formation since the earliest phases of life. Even more interesting, obesity at adolescence is a strong predictor of coronary heart disease during adulthood. ${ }^{(11,12)}$ Therefore, obesity in childhood might represent the trigger for the development of permanent vascular abnormalities that, in turn, increase cardiovascular risk in adulthood. ${ }^{(11)}$

It is universally accepted that disturbed endothelial cell biology, variably including activation, injury, damage, and dysfunction, forms part of the early pathogenesis of atherosclerosis. Therefore, the assessment of endothelial dysfunction by either noninvasive or invasive means may represent a clinically relevant tool to predict the overall vascular risk. $^{(\mathbf{9 , 1 1})}$

Therefore, it is tempting to hypothesize that obesity-related activation of vascular endothelial cells and platelets may occur during childhood and contribute to increased cardiovascular risk later in life. However, to the best of our knowledge, no studies have tested this possibility. To assess this topic, we evaluated circulating levels of sICAM-1, sVCAM-1, and sE-selectin, as indices of endothelial activation in obese children., Finally, because CRP deeply affects vascular biology by favoring a proinflammatory and proatherosclerotic phenotype ${ }^{(\mathbf{1 3}, 14)}$, we evaluated the relationship between circulating levels of highly sensitive (hs)-CRP and soluble markers of vascular endothelial cell and platelet activation in our study population. We aimed to investigate the relationship of morphological vascular status (Carotid Artery IMT) and functional vascular changes as plasma endothelial markers (vWf, sICAM-1 and E-selectin) and sP-selectin as markers of platelet activation in obese children, compared with controls. 


\section{METHODS}

Study Design

We recruited 35 consecutive obese children (age range 7-15 years) when they presented to outpatient department of pediatric endocrinology and cardiology, Batnan Medical Center, Tobruk, Lybia, after obtaining written informed consent from the parents. Obesity was defined as a BMI in excess of the $97^{\text {th }}$ percentile for the German pediatric population. ${ }^{(15)}$

The control group consisted of lean children $(n=25)$ was selected among children presenting at the same institution for diagnostic workup of non specific complaints. Children with chronic or recurrent illness were excluded from the studied groups. We ensured comparability of the 2 groups by frequency matching for major baseline characteristics, including family history of atherosclerotic disease, risk behavior (smoking), gender, and Tanner stages based on the assumption that significant differences between the 2 groups in these variables would have an impact on the study conclusions. The study plan was approved by the local ethics committee, and written informed consent was obtained from the parents after a detailed interview.

\section{Measurement of Risk Factors}

Anamnestic and anthropometric data were reviewed during a 2-day hospital stay. Body fat was assessed by bioelectrical impedance. (Data Input Inc, Frankfurt/Main, Germany) and was expressed as percentage of body weight. A venous blood sample was collected after overnight fasting. Insulin resistance was calculated using the homeostasis model assessment ${ }^{(\mathbf{1 5})}$ and insulin sensitivity was determined using data of an oral glucose tolerance test (insulin sensitivity index) to exclude any children with any degree of impaired glucose tolerance.

Vascular Measurements

Echocardiograph vascular measurements were done with a Hewlett-Packard Sonos system (Sonos 5500; Philips, Int, Hamburg, Germany $)^{(\mathbf{1 6})}$. All of the children were examined in a quiet, temperature-controlled room. For IMT, a high-frequency (15 MHz) vascular linear transducer was used for imaging the carotid arteries. Patients were examined in the supine position, with the head turned $45^{\circ}$ away from the side being scanned. Two segments were identified on each side: the distal $1 \mathrm{~cm}$ of the common carotid artery and the bifurcation itself. Five measurements were taken at 2-mm intervals at near and far wall (distance from the transducer) in each of the 2 segments. Maximum and mean IMT were calculated separately for each side of each segment. Sonography and reading were performed by trained and board-certified sonographers. Intraobserver and interobserver variability (mean bias) were $0.2 \%$ and $1.2 \%$, respectively.

\section{Measurement of Plasma Endothelial Markers}

Fasting plasma samples were obtained from citrate-anticoagulated venous blood samples after centrifugation $\quad(3000 \mathrm{rpm}, 15$ minutes). Aliquots were snap frozen, stored at $-80^{\circ} \mathrm{C}$, and thawed only once immediately before analyses, which were performed in 1 batch. After an overnight fast, blood samples were 
taken in obese children and in control subjects to measure serum total cholesterol, HDL cholesterol, LDL cholesterol, and triglyceride concentrations. vWF:Ag was determined by an immunoturbidimetric assay with antibody-coated polystyrene beads using a Behring coagulation analyzer (Dade Behring, Marburg, Germany).

Plasma aliquots were stored at $80^{\circ} \mathrm{C}$ in polypropylene tubes immediately after centrifugation (15 $\min$ at $4^{\circ} \mathrm{C}$ at $3000 \mathrm{rpm}$ ) of blood samples and subsequently used to assess circulating levels of sICAM-1, sVCAM-1, sE-selectin, sP-selectin and hs-CRP concentrations were measured by an immunoenzymatic method (R\&D Systems, Minneapolis, $\mathrm{MN}$ ).

\section{Statistical Methods}

Data were stored and analyzed using the SPSS 12.0 statistical package (SPSS Inc, Chicago, IL). Descriptive statistics were computed for variables of interest and included mean values and SDs of continuous variables and absolute and relative frequencies of categorical factors.

Testing for differences of continuous variables between the study groups was accomplished by the 2 -sample $t$ test for independent samples or the Mann-Whitney U test, as appropriate. Test selection was based on evaluating the variables for normal distribution using the Kolmogorov-Smirnov test. For categorical factors, comparisons between groups were performed by Fisher's exact test. All of the $P$ values resulted from 2-sided statistical tests, and $P \leq .05$.

\section{RESULTS}

The two study groups were matched in terms of age, sex and body height (Table 1). Highly significant differences were found for weight and BMI, as well as for SBP and DBP. DBP was significantly higher in obese male patients than in obese females and controls (ANOVA, Tamhane's T2 pair wise comparison, $\mathrm{P}<0.001$ ).

Table (1): Characteristics of the study groups (mean \pm SD; median (range) for age; Chi-squared test for sex, Mann-Whitney test for age, Independent Sample $t$ test for all other variables)

\begin{tabular}{|l|l|l|l|}
\hline & \multicolumn{1}{|c|}{ Control group } & \multicolumn{1}{|c|}{ Obesity group } & P \\
\hline $\mathrm{N}$ & \multicolumn{1}{|c|}{25} & 35 & \\
\hline $\begin{array}{l}\text { Sex } \\
\text { boys } \\
\text { boys }\end{array}$ & 13 girls, 15 & 17 girls, 26 & 0.628 \\
\hline Age (years) & $12(7-14)$ & $12(7-15) 0$. & 105 \\
\hline Height $(\mathrm{cm})$ & $147.9 \pm 5.7$ & $147.8 \pm 12.8$ & 0.947 \\
\hline Weight $(\mathrm{kg})$ & $35.0 \pm 6.6$ & $60.5 \pm 11.9$ & $<0.001$ \\
\hline BMI $(\mathrm{kg} / \mathrm{m} 2)$ & & $27.7 \pm 5.1$ & $<0.001$ \\
\hline SBP $(\mathrm{mmHg})$ & $16.0 \pm 2.4$ & $119.8 \pm 13.3$ & $<0.001$ \\
\hline DBP $(\mathrm{mmHg})$ & $104.8 \pm 7.7$ & $73.5 \pm 8.2$ & $<0.001$ \\
\hline
\end{tabular}




\section{Carotid ultrasound study:}

The ultrasound Doppler study of the common and internal carotid vessels did not show significant haemodynamic differences in peak flow velocity and average flow velocity but the mean carotid IMT showed a significant increase in obese subjects in CCA and ICA (Table 2) significantly larger CCA diameter in obese children, compared with control subjects, while ICA diameters were significantly larger for obese girls and boys, compared with controls. After adjustment for BMI, SBP and DBP as covariates on ANCOVA, the only significant). These differences remained highly significant after adjustment for BMI, SBP and DBP (all $\mathrm{P}<0.001$ ).

We calculated an average of IMT for CCA and ICA and used this value for correlation analysis. No advanced atherosclerotic lesions, such as plaques, calcifications or stenosis, were observed in our study subjects.

Table (2):

\begin{tabular}{|c|l|l|l|}
\hline & Control group & Obese group & P \\
\hline Measured diameter & & & \\
CCA & $5.83 \pm 0.67$ & $6.49 \pm 0.90 *$ & 0.013 \\
ICA & $5.10 \pm 0.68$ & $5.95 \pm 1.15$ & 0.001 \\
Diameter estimate & $6.403(0.257)$ & $6.130(0.185 .)^{* *}$ & 0.040 \\
CCA & $5.457(0.331)$ & $639(0.235)$ & 0.5713 \\
ICA & & & \\
\hline
\end{tabular}

* Significantly larger than in the other three groups

(Tamhane's T2 pair wise, $P<0.05$ )

**Significantly smaller than in the other three groups

(Tamhane's T2 pair wise, $P<0.05$ )

Soluble markers of vascular endothelial cells and activation

Obese children showed higher plasma levels of sICAM-1 (206.4 \pm 33.6 vs. $122.8 \pm 16.0 \mu \mathrm{g} / \mathrm{liter}$; $P<0.001)$, sVCAM-1 (402.6 \pm 75.7 vs. $289.5 \pm 44.8 .0 \mu \mathrm{g} / \mathrm{liter} ; P<0.001)$, and sE-selectin $(84.0 \pm 20.0$ vs. $55.3 \pm 10.6$ $\mu \mathrm{g} /$ liter; $\quad P<0.001)$ when compared with non obese subjects (Fig. 1). In contrast, vWf:Ag showed no significant difference between obese and control children Similarly, significant platelet activation was present in obese children as indicated by their higher plasma levels of sPselectin $(73.2 \pm 11.2$ vs. $48.5 \pm 8.9$ $\mu \mathrm{g} /$ liter; $P<0.001)$ in comparison with non obese children, also CRP concentrations $\quad(95 \%$ CI $1.97-3.24$ $\mathrm{mg} / \mathrm{l}$ obese vs. $95 \%$ CI $0.488-1.356$ $\mathrm{mg} / \mathrm{l}$ control) were significantly higher in obese children in comparison with non obese children. 
Table (3): Parameters of Soluble markers of vascular endothelial cells and activation performed for statistical comparison

\begin{tabular}{|l|l|l|l|}
\hline & Control Group & Obesity group & $P$ \\
\hline sICAM-1 $(\mu \mathrm{g} /$ liter $)$ & $206.4 \pm 33$. & $122.8 \pm 16.0$ & $<0.001$ \\
sVCAM-1 $\mu \mathrm{g} /$ liter & $402.6 \pm 75.7$ & $289.5 \pm 44.8 .0$ & $<0.001$ \\
sE-selectin $(\mu \mathrm{g} /$ liter $)$ & $84.0 \pm 20.0$ & $55.3 \pm 10.6$ & $<0.001$ \\
sP-selectin $(\mu \mathrm{g} /$ liter $)$ & $73.2 \pm 11.2$ & $48.5 \pm 8.91 .97$ & $<0.001$ \\
CRP $(\mathrm{mg} / \mathrm{l})$ & $0.488 \pm 1.356$ & $3.24 \pm 1.8$ & $<0.001$ \\
\hline
\end{tabular}

\section{DISCUSSION}

Childhood obesity has become a public health problem in developed countries, while its prevalence also shows an increasing trend in developing countries. Obesity is associated with an increased risk for cardiovascular disease and mortality in adults. Insulin resistance, the main characteristic of the metabolic syndrome, can also be observed in children with obesity. ${ }^{(17)}$ Childhood obesity frequently persists into adulthood. In addition, the risk for developing metabolic syndrome and Type-2 Diabetes Mellitus (T2DM) in adulthood is increased in obese children. Obesity-related vascular abnormalities form part of a cluster of risk factors in overweight children, putting them at high risk for the development of premature atherosclerotic disease. ${ }^{(\mathbf{1 8})}$

The aim of the present study in obese children was two fold. Two independent vascular measures were used to document early functional and morphologic arterial changes in obese children, and plasma endothelial markers were used to assess endothelial cell function and integrity. The vascular endothelium remains a difficult organ to study, and the use of surrogate plasma endothelial markers, reflecting either endothelial cell activation or injury, has attracted much attention. ${ }^{(\mathbf{1 9})}$

In the present study, obese children demonstrated elevated concentrations of the plasma endothelial markers soluble Eselectin, whereas those of vWfAg showed no significant differences between obese and control children.

E-selectin is an endothelial cellspecific adhesion molecule. The mechanisms of the generation of its soluble form have not been well established. Increased concentrations of soluble E-selectin have been repeatedly reported for obese adults. ${ }^{(20)}$ However, increased soluble E-selectin in obese children, as an indicator of early vascular endothelial cell activation, has only recently been reported for the first time. ${ }^{(21)}$ Experimental studies have provided firm evidence that soluble E-selectin was increased after endothelial cell activation by cytokines. ${ }^{\text {(2) }}$ Accordingly, in our study population, an association of elevated levels of soluble E-selectin with indicators of a low-grade pro inflammatory phenotype Hs C-reactive protein was established. 
Increased vWFAg concentrations have been repeatedly demonstrated in hypertensive and obese adults. However, its prognostic impact in asymptomatic patients with regard to subsequently developing strokes and other atherosclerotic manifestations is a matter of ongoing controversy. ${ }^{(23)}$ Interpretation in individual subjects must be cautious, because vWFAg concentrations are influenced by various physiologic stimuli, including vasopressin, thrombin, and proinflammatory cytokines.(24) Accordingly, its reliability as a marker of early atherosclerotic disease development in children has yet to be proven.

Also, the present study found that obese children had significantly elevated sICAM-1, and sVCAM-1 levels, in comparison with control group. A significant correlation was also noted between sICAM and sVCAM levels and variables indicative of low-grade inflammation (CRP) and proinflammatory cytokines (IL-6).

Vascular endothelial dysfunction is considered the earliest stage in the atherogenic process ${ }^{(25)}$. One of the molecules acting on the endothelium is sICAM, elevated levels of which are indicative of endothelial dysfunction, implying enhanced leukocyte adhesion $^{(26)}$ which in turn is pathologically decisive in atherogenesis $^{(27)}$.

In obese subjects, increased sICAM and sVCAM levels prompt a pathological increase in endothelial adhesion and permeability, thus favoring atherogenesis. sICAM-1 has been associated with an increased risk of ischemic disease and peripheral artery disease ${ }^{(\mathbf{2 8})}$.

It has been suggested that sICAM, and sVCAM mediated endothelial dysfunction is prompted by cytokines secreted in part by adipose tissue. Inflammation is associated with endothelial dysfunction. CRP, which appears to be a key sICAM regulator ${ }^{(29)}$, may be involved in this process. Liver CRP synthesis is in turn enhanced by the action of proinflammatory cytokines such as IL-6, secreted by adipose tissue.

Our results are consistent with those reported in obese Caucasian children, in whom increased levels of sICAM, sVCAM, soluble E-selectin, and soluble P-selectin have been reported $^{(30)}$. An elevation of circulating soluble adhesion molecules represents an early stage in atherosclerosis. These molecules are produced by injured endothelial cells, leading to the rolling, activation, and firm adhesion of circulating leukocytes to the endothelium ${ }^{(33)}$. Recent data suggest that CRP, and ICAM-1 are molecular markers associated with atherosclerosis and its progression $^{(31)}$. Elevated sICAM levels (and not sVCAM) also predict the development of type 2 diabetes in adults (32). Our data therefore demonstrate the presence of endothelial activation in this group of overweight children and adolescents that may reflect an increased risk for both type 2 diabetes and cardiovascular disease. Vascular inflammation is a key element in the development of cardiovascular disease. ${ }^{(34)}$ 
Also, the present study revealed increased IMT in obese children as compared with control. IMT in obese children is a matter of ongoing debate.

In agreement with our study, extending data from previous studies describing vascular abnormalities in obese children were reported. ${ }^{(35)}$

Moreover, a recent study compared obese children from a Hong Kong school community with nonobese peers and found a significantly increased $\mathrm{IMT}^{(36)}$. Another report from the same research group showed a significant reduction in carotid IMT among obese subjects after physical exercise and diet, suggesting a certain degree of reversibility of early atherosclerotic changes. ${ }^{(37)}$

In contrast with our study a study of obese children obtained no evidence of significant differences in carotid IMT as compared with control subjects $^{(\mathbf{3 8})}$, data from the present study lend support to results from a larger study demonstrating increased carotid IMT in obese children. ${ }^{(39)}$

The present study provides evidence that a number of parameters may be used for disclosing those children at high risk. IMT measurements and the analysis of endothelial dysfunction, and vascular inflammatory markers soluble Eselectin and thrombomodulin may reflect the overall influence of different risk factors on the early development of atherosclerosis.

From a clinical point of view, weight control and the support of physical fitness will remain the cornerstones in the management of obese children at risk of early atherosclerotic disease. In contrast, noninvasive assessment of endothelial integrity is a research tool to document the vascular effects of weight control and therapeutic measures.

In conclusion, we have found that obese children and adolescents have elevated markers of endothelial dysfunction and vascular inflammation closely related to morphologic arterial changes (IMT). This may increase their risk of development of permanent vascular abnormalities that, in turn, increase cardiovascular risk in adulthood, Insulin resistance, and type 2 diabetes and further emphasizing the need for obesity prevention strategies.

\section{REFERENCES}

1. Slyper AH 2004 The pediatric obesity epidemic: causes and controversies. J Clin Endocrinol Metab 89:2540-2547

2. Srinivasan SR, Bao W, Wattigney WA, Berenn GS 1996 Adolescent overweight is associated with adult overweight and related multiple cardiovascular risk factors: the Bogalusa Heart Study. Metabolism 45:235-240

3. Barlow SE, Dietz WH 1998 Obesity evaluation and treatment: Expert Committee recommendations. The Maternal and Child Health Bureau, Health Resources and Services Administration and the Department of Health and Human Services. Pediatrics 102:E29

4. Freedman DS, Dietz WH, Srinivasan SR, Berenson GS 1999: The relation of overweight to cardiovascular risk factors 
among children and adolescents: the Bogalusa Heart Study. Pediatrics 103:1175-1186

5. Csabi G, Torok K, Jeges S, Molnar D 2000 Presence of metabolic cardiovascular syndrome in obese children. Eur Pediatr 159:91-95

6. Tresaco B, Bueno G, Moreno LA, Garagorri JM, Bueno M 2003 Insulin resistance and impaired glucose tolerance in obese children and adolescents. J Physiol Biochem 59:217-223

7. Vanhala MJ, Vanhala PT, Keinänen-Kiukaanniemi SM, Kumpusalo EA, Takala JK 1999 Relative weight gain and obesity as a child predict metabolic syndrome as an adult. Int J Obes 23:656-672

8. McGill Jr HC, MCMahan CA, Herderick EE, Malcom GT, Tracey RE, Strong JP 2000 Origin of atherosclerosis in childhood and adolescence. Am J Clin Nutr 72:1307-1315

9. Tounian P, Aggoun Y, Dubern B, Varille V, Guy-Grand B, Sidi D, Girardet JP, Bonnet D 2001 Presence of increased stiffness of the common carotid artery and endothelial dysfunction in severely obese children: a prospective study. Lancet 358:1400-1404

10. Woo KS, Chook P, Yu CW, Sung RY, Qiao M, Leung SS, Lam CW, Metreweli C, Celermajer DS 2004 Effect of diet and exercise on obesityrelated vascular dysfunction in children. Circulation 109:19811986
11. Must A, Jacques PF, Dallal GE, Bajema CJ, Dietz WH 1992 Long-term morbidity and mortality of overweight adolescents. A follow-up of the Harvard Growth Study of 1922 to 1935. N Engl J Med 327:13501356

12. Gunnell DJ, Frankel SJ, Nanchahal K, Peters TJ, Davey Smith G 1998 Childhood obesity and adult cardiovascular mortality: a 57-year follow-up study based on Boyd Orr cohort. Am J Clin Nutr 67:1111-1118

13. Ross R 1999 Atherosclerosis: an inflammatory disease. $\mathrm{N}$ Engl J Med 340:115-126

14. Szmitko PE, Wang CH, Weisel RD, de Almeida JR, Anderson TJ, Verma S 2003 New markers of inflammation and endothelial cell activation. Part I. Circulation 108:1917-1923

15. Desai MY, Dalal D, Santos RD, Carvalho JA, Nasir K, Blumenthal RS: Association of body mass index, metabolic syndrome and leukocyte count. Am J Cardiol 97:835-838, 2006

16. Pauciullo $P$, Iannuzzi A, Sartorio R, Irace C, Covetti G, Di Costanzo A, Rubba P (1994) Increased intima-media thickness of the common carotid artery in hypercholesterolemic children.Arterioscler Thromb Vasc Biol 14: 1075-1079

17. Ells LJ, Campbell K, Lidstone J, et al 2006 Preventive Services Task Force, Screening and interventions for overweight in children and adolescents: recommendation statement. Am Fam Physician 73: 115-119. 
18. Weiss R, Dziura J, Burgert TS, et al, 2004 Obesity and the metabolic syndrome in children and adolescents. N Engl J Med 350: 2362-2374

19. Wu JT, Wu LL. Association of soluble markers with various stages and major events of atherosclerosis. Ann Clin Lab Sci. 2005; $35: 240-250$

20. Ferri C, Desideri G, Valenti M, Bellini C, Pasin M, Santucci A, et al. Early upregulation of endothelial adhesion molecules in obese hypertensive men. Hypertension. 1999;34:568-573

21. Desideri G, De Simone $M$, Iughetti L, et al. Early activation of vascular endothelial cells and platelets in obese children. J Clin Endocrinol Metab. 2005;90:3145 $-3152$

22. Newman W, Beall LD, Carson $\mathbf{C W}$, et al. Soluble E-selectin is found in supernatants of activated endothelial cells and is elevated in the serum of patients with septic shock. J Immunol. 1993; $150: 644-654$

23. Folsom AR, Rosamond WD, Shahar E, et al. Prospective study of markers of hemostatic function with risk of ischemic stroke. The Atherosclerosis Risk in Communities (ARIC) Study Investigators. Circulation. 2006; $100: 736-742$

24. Wagner DD. Cell biology of von Willebrand factor. Annu Rev Cell Biol. 1990;6 :217-246

25. Kent JW Jr, Comuzzie AG, Mahaney MC, Almasy L, Rainwater DI, VandeBerg JL, MacCluer JW \& Blangero $\mathbf{J}$. Intercellular adhesion molecule-1 concentration is genetically correlated with insulin resistance, obesity, and HDL concentration in Mexican Americans. Diabetes 200453 2691-2695.

26. Witkowska AM \& Borawska MH. Soluble intercellular adhesion molecule-1 (sICAM-1): an overview. European Cytokine Network 200415 91-98.

27. 27 De Caterina R. Endotelial dysfunctions: common denominators in vascular disease. Current Opinion in Lipidology 2000 11 9-23.

28. McSorley PT, Young IS, McEneny J, Fee H \& McCance DR. Susceptibility of low-density lipoprotein to oxidation and circulating cell adhesion molecules in young healthy adult offspring of parents with type 2 diabetes. Metabolism 2004, 53 ,755-759.

29. Pasceri V, Willerson JT \& Yeh ET. Direct proinflammatory effect of C-reactive protein on human endothelial cells. Circulation 2000, 102, 21652168.

30. 30 Glowinska B, Urban M, Peczynska J, Florys B: Soluble adhesion molecules (sICAM-1, sVCAM-1) and selectins (sE selectin, sP selectin, sL selectin) levels in children and adolescents with obesity, hypertension, and diabetes. Metabolism 54:10201026, 2005

31. Desideri G, De Simone M, Iughetti L, Rosato T, Iezzi ML, Marinucci MC, Cofini V, Croce G, Passacquale G, Necozione $S$, Ferri C: Early activation of vascular endothelial cells and 
platelets in obese children. J Clin Endocrinol Metab 90:3145-3152, 2005

32. Meigs JB, Hu FB, Rifai $\mathbf{N}$, Manson JE: Biomarkers of endothelial dysfunction and risk of type 2 diabetes mellitus. JAMA,291:1978-1986, 2004.

33. Desideri G, De Simone M, Iughetti L, Rosato T, Iezzi ML, Marinucci MC, Cofini V, Croce G, Passacquale G, Necozione $S$, Ferri C: Early activation of vascular endothelial cells and platelets in obese children. J Clin Endocrinol Metab 90:3145-3152, 2005.

34 A. Enrique, Kelb B, L Robles, Osama Hamdy: Overweight Latino Children and Adolescents Have Marked Endothelial Dysfunction and Subclinical Vascular Inflammation in Association With Excess Body Fat and Insulin Resistance. Diabetes Care 31:576-582, 2008.

35 Sorof JM, Alexandrov AV, Cardwell G, Portman RJ (2003) Carotid artery intimalmedial thickness and left ventricular hypertrophy in children with elevated blood pressure. Pediatrics 111: 61-66

36 Woo KS, Chook P, Yu CW, Sung RY, Qiao $M$, Leung SS,Lam CW, Metreweli C, Celermajer DS (2004) Overweight in children is associated with arterial endothelial dysfunction and intima-media thickening. Int $\mathrm{J}$ Obes Relat Metab Disord 28:852-857

37 Woo KS, Chook P, Yu CW, Sung RY, Qiao M, Leung SS,Lam CW, Metreweli C, Celermajer DS (2004) Effects of diet and exercise on obesityrelated vascular dysfunction in children.Circulation 109: 19811986

38 Maffeis C, Tato L 2001 Longterm effect of childhood obesity on morbidity and mortality. Horm Res 55:42-45

39 Chen W, Srinivasan SR, Li S, Xu J, Berenson GS (2005) Metabolic syndrome variables at low levels in childhood are beneficially associated with adulthood cardiovascular risk: the Bogalusa Heart Study. Diabetes Care 28: 126-131. 


\section{دلائل التهابات الاوعية الدموية فى مرحلة ماقبل السريريةِ ، وسماكة طبقات الإني}

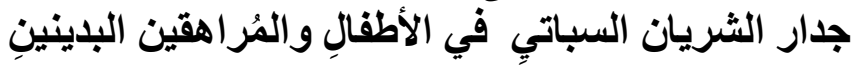

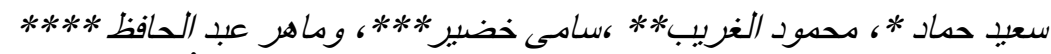

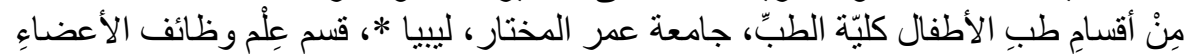

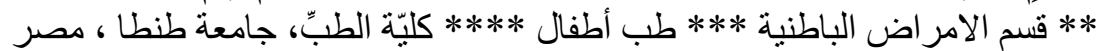

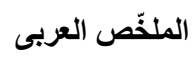

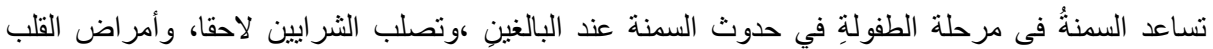

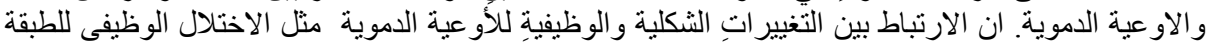

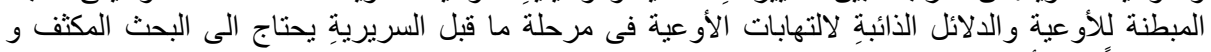
خصوصاً في الأطفال البدينين.

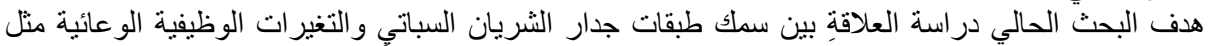

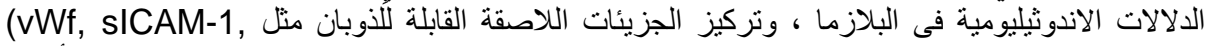
SVCAM-1, sP-selectin, hs-CRP concentrations and E-selectin )

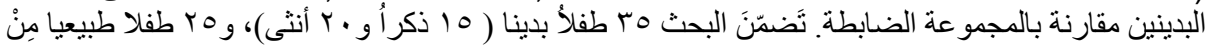

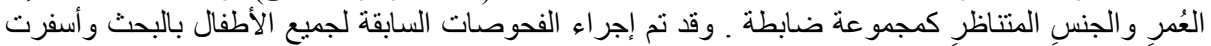

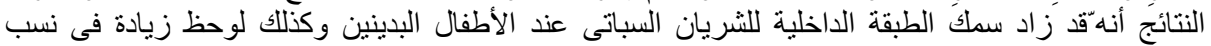

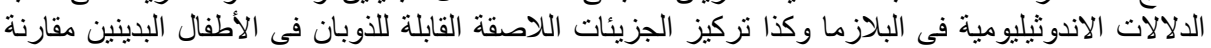

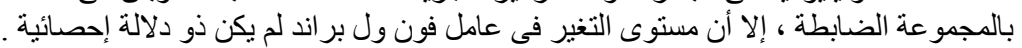

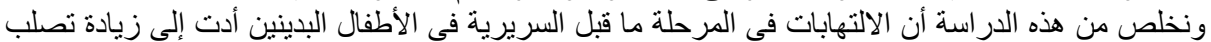

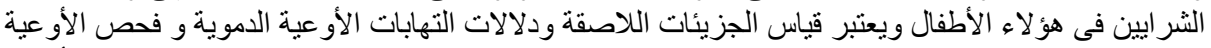

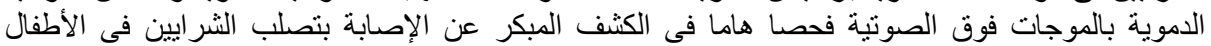
البدينين . 